Utah State University

DigitalCommons@USU

2-11-2013

\title{
Acceptance and Commitment Therapy as a Treatment for Scrupulosity in Obsessive Compulsive Disorder
}

John P. Dehlin

Utah State University

Kate L. Morrison

Utah State University

Michael P. Twohig

Utah State University

Follow this and additional works at: https://digitalcommons.usu.edu/psych_facpub

Part of the Psychology Commons

\section{Recommended Citation}

Dehlin, J. P, *Morrison, K. L., \& Twohig, M. P.(2013). Acceptance and commitment therapy as a treatment for scrupulosity in obsessive compulsive disorder. Behavior Modification, 37, 409-430.

This Article is brought to you for free and open access by the Psychology at DigitalCommons@USU. It has been accepted for inclusion in Psychology Faculty Publications by an authorized administrator of DigitalCommons@USU. For more information, please contact digitalcommons@usu.edu.

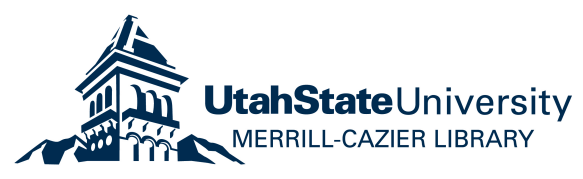


Acceptance and Commitment Therapy as a Treatment for Scrupulosity in Obsessive Compulsive Disorder John P. Dehlin 1, Kate L. Morrison 1, and Michael P. Twohig 1

Abstract

This study evaluated acceptance and commitment therapy (ACT) for scrupulosity-based obsessive compulsive disorder (OCD). Five adults were treated with eight sessions of $A C T$, without in-session exposure, in a multiple baseline across participants design. Daily monitoring of compulsions and avoided valued activities were tracked throughout the study. The Obsessive Compulsive Inventory-Revised, Yale-Brown Obsessive Compulsive Scale (Y-BOCS), Penn Inventory of Scrupulosity, Beck Depression Inventory-II, Quality of Life Scale, Santa Clara Strength of Religious Faith Questionnaire, and the Acceptance and Action Questionnaire-II were completed at pretreatment, posttreatment, and 3-month follow-up. The Treatment Evaluation Inventory was completed at posttreatment. Average daily compulsions reduced as follows: pretreatment $=25.0$, posttreatment $=5.6$, and follow-up $=4.3$. Average daily avoided valued activities reduced as follows: pretreatment $=6.0$, posttreatment $=0.7$, and followup $=0.5$. Other measures showed similar patterns. Religious faith only slightly declined: $4 \%$ at posttreatment and $7 \%$ at follow-up. Treatment acceptability was high.

\section{Keywords}

Scrupulosity, obsessive compulsive disorder, acceptance and commitment therapy, treatment

1 Utah State University, Logan, Utah, USA

Corresponding author(s):

John P. Dehlin and Michael P. Twohig, Department of Psychology, Utah State University, 2810 Old Main Hill, Logan, Utah 84322-2810, USA. Email: john.dehlin@aggiemail.usu.edu, michael.twohig@usu.edu

Scrupulosity is a distressing form of obsessive compulsive disorder (OCD) characterized by unreasonable, egodystonic, anxiety-producing intrusive thoughts about religious or moral issues, accompanied by compulsive thoughts or behaviors performed with the intent of neutralizing anxiety (Abramowitz, Huppert, Cohen, Tolin, \& Cahill, 2002; Ciarrocchi, 1995). Four of the most common, general manifestations of scrupulosity include (a) compulsive behaviors that far exceed religious norms or requirements (e.g., praying for hours a day), (b) narrowly focused compulsions (e.g., avoiding the risk of an inappropriate sexual thought at the expense of fulfilling other religious duties), (c) excessive focus on religious trivialities (e.g., compulsions to avoid spilling a drop of holy water), and (d) a tendency to misconstrue, and/or overly literalize scriptural passages (Cefalu, 2010).

Scrupulosity is estimated to occur in $5 \%$ to $33 \%$ of OCD patients, or $0.05 \%$ to $0.33 \%$ of the general population (Miller \& Hedges, 2008). Although scrupulosity has reasonably high levels of prevalence and clinical distress (Cefalu, 2010; Fallon, Liebowitz, Hollander, \& Schneier, 1990), it has received minimal attention from researchers in terms of its etiology and treatment (Miller \& Hedges, 2008). At present, the first-line treatment for $O C D$ is cognitive-behavior therapy using exposure and response prevention (ERP) or serotonergenic medications (Abramowitz, 2008). It should be noted that these findings are from larger treatment trials for $O C D$ and not from scrupulosity trials specifically. One small $(N=10)$ study on scrupulosity has been conducted to date (Fallon et al., 1990), wherein 5 of 10 patients were rated as 
much improved after 8 weeks of treatment with fluoxetine, with 1 additional participant responding to adjunctive clomipramine. A handful of case studies have been published on the treatment of scrupulosity with ERP as well, though few are conclusive (Abramowitz, 2001; Bonchek \& Greenberg, 2009; Garcia, 2008; Greenberg \& Witztum, 2001; Huppert \& Siev, 2010). In one case citing outcome data, Abramowitz (2001) found a posttreament reduction of $65 \%$ in Yale-Brown Obsessive Compulsive Scale (Y-BOCS; Goodman, Price, Rasmussen, \& Mazure, 1989a, 1989b) scores, along with a reduction in Beck Depression Inventory (BDI) scores from 28 at intake to 10 at posttreatment. Finally, no known clinical psychology trials for scrupulosity have been conducted to date, suggesting room for additional scrupulosity research.

Acceptance and commitment therapy (ACT) for OCD is a form of cognitive-behavioral therapy that holds promise for scrupulosity-based OCD (Twohig, 2009). ACT for OCD seeks to address the context in which obsessions are experienced through the teaching and practice of such concepts as acceptance of thoughts and feelings, learning to disempower thoughts and feelings by not giving them more significance than they merit, mindfulness, and values-based committed action. These skills are taught through exercises, discussions, and experiential exercises and metaphors in the therapy sessions. Through weekly homework assignments, clients are able to further apply the techniques learned in session to real-life situations and problems.

ACT has been shown to be a viable treatment for OCD in at least two studies (Twohig et al., 2010; Twohig, Hayes, \& Masuda, 2006). In these studies, ERP or similar practices were not used so that the effects of ACT could be determined without the influence of already supported procedures. If ACT was first tested with exposure exercises, it would have been difficult to determine what components were producing the outcomes. Because the effects of ACT alone have been demonstrated, other studies have been testing the effects of combining ACT and traditional exposure exercises (e.g., Meuret, Twohig, Hayes, Rosenfield, \& Craske, 2012).

In a multiple baseline across participants design using ACT for OCD (Twohig et al., 2006), significant reductions in compulsions were achieved by all participants with results maintained at 3-month followup. OCD symptom severity (as measured by the Obsessive Compulsive Inventory-Revised [OCl-R]) improved by $68 \%$ from pretreatment to posttreatment, and increased to $81 \%$ at follow-up. In a randomized clinical trial for OCD (Twohig et al., 2010), eight sessions of ACT for OCD were compared with a control treatment of Progressive Relaxation Training (PRT; $N=79)$. ACT demonstrated greater positive change in OCD severity as measured by the Y-BOCS (ACT pre $=24.22$, post $=12.76$, follow-up $=$ 11.79; PRT pre $=25.4$, post $=18.67$, follow-up $=16.23$ ), and clinically significant change rates (Jacobson \& Truax, 1991) were also significantly in favor of ACT (ACT post $=46 \%-56 \%$, follow-up $=46 \%-66 \%$; PRT post $=13 \%-18 \%$, follow-up $=16 \%-18 \%)$. ACT demonstrated low treatment refusal $(\mathrm{ACT}=2.4 \%, \mathrm{PRT}=$ $7.8 \%)$ and drop-out $(\mathrm{ACT}=9.8 \%, \mathrm{PRT}=13.2 \%)$ rates, and significantly greater treatment acceptability than PRT (ACT $=4.38, \mathrm{PRT}=3.28$ on a 5-point scale).

ACT appears to be an especially good fit for the treatment of scrupulosity-based OCD. Because ACT targets the process of thinking, similar to other metacognitive therapies, ACT for scrupulosity-based OCD can be successfully implemented without content knowledge of religious doctrine, and without excessive attention given to "proper" religious practice. This can be useful because individuals with scrupulosity-based OCD are often stuck in the details of religious doctrine or practice, usually to the detriment of meaningful religious activity. ACT helps clients find ways to live regardless of their 
obsessional concerns, and uses the metric of "meaningful activities" to track treatment success. Thus, ACT for scrupulosity-based OCD largely sidesteps religious content and cognitions, and instead focuses on how clients live their lives. It is through this process that clients may eventually learn ways to align their personal values and religious practices in a way that is personally meaningful. Given the supportive outcomes seen in ACT for OCD generally, the seemingly good fit for ACT, and the dearth of data on the treatment of scrupulosity-based OCD, a preliminary test of ACT for scrupulosity-based OCD seems warranted.

To provide initial data on the suitability of ACT for scrupulosity, this study used a multiple baseline across participants design with five participants with scrupulosity-based OCD. The treatment was based on ACT for OCD (Twohig et al., 2006; Twohig et al., 2010), and was tailored for scrupulosity-based OCD specifically. Consistent with ACT's focus on quality of life, the primary dependent variables for this study were (a) the frequency of daily compulsions and (b) avoided valued activities, tracked by each participant throughout the study. Self-report data were supported by standardized measures completed at pretreatment, posttreatment, and 3-month follow-up. Psychological flexibility was measured throughout treatment to track changes in ACT's purported process of change. It is predicted that eight sessions of ACT for OCD will result in visibly significant reductions in daily compulsions and avoided valued activities for a majority of participants and that psychological flexibility will increase. It is predicted that ACT for OCD will also result in lower scores on OCD, scrupulosity, and depression measures, higher scores on quality-of-life measures, and no significant changes on religiosity measures. Finally, it is predicted that participants will rate the treatment as acceptable.

\section{Method}

\section{Participants}

Participants for this study were recruited through advertisements in local newspapers, websites, radio, flyers placed around the community, and through announcements made to undergraduate psychology classes at a university in the western United States. Inclusion criteria for the study were as follows: (a) above the age of 18, (b) a diagnosis of OCD based on the Structured Clinical Interview for DSM-IV (SCID; First, Spitzer, Gibbon, \& Williams, 2002), and (c) an initial Y-BOCS endorsement of scrupulosity-based OCD. Exclusion criteria were the following: (a) non-English speaking, (b) a primary DSM-IV diagnosis other than $O C D$, (c) current participation in psychotherapy elsewhere, or having received treatment within the past 30 days, (d) any change in psychotropic prescription usage over the past 30 days, or a plan to change current prescription levels over the course of treatment, or (e) any type of detectable disability that would severely interfere with participation in the study. Eighteen participants were formally screened for the study. Nine did not qualify either because they did not meet criteria for OCD, or because their obsessions and compulsions were not religious in nature. Two qualified after the initial screening but chose not to participate in the study due to either excessive travel requirements, or not wanting to monitor their daily compulsions. Seven were accepted into the study and began baseline tracking, and two dropped out of the study prior to beginning treatment (one due to not wanting to continue tracking his compulsions and the other because his symptom severity improved to the point of no longer desiring treatment). Table 1 details the primary participant characteristics of those who began treatment.

Measures 


\section{Diagnostic Measures.}

SCIDThe SCID (First et al., 2002) is a semistructured interview for making Diagnostic and Statistical Manual of Mental Disorders (4th ed.; DSM-IV; American Psychiatric Association, 1994) Axis I diagnoses. It is widely held as the gold standard for both psychological and psychiatric diagnosis, and has demonstrated suitable reliability and validity in multiple studies (Segal, Hersen, \& Van Hasselt, 1994).

\section{Outcome Measures.}

Self-monitoringCompulsions and avoided valued activities were operationally defined for each participant, and these definitions were used to track the occurrence of these behaviors. Compulsions were individually defined, and avoided valued activities were defined as valued activities that were avoided because of fear that they might trigger the obsessions or compulsions (e.g., praying, going to church or the temple). At the end of each day, participants were sent an email reminding them to enter their data into a secure online web form. These data were the primary dependent variables for this study, upon which treatment decisions were based. While specific reliability and validity statistics are not available for this study, self-monitoring of specific behaviors, after appropriate training, has been found to result in accurate assessment of behavior (Jackson, 1999; Korotitsch \& Nelson-Gray, 1999).

$\mathrm{OCl}-\mathrm{RThe} \mathrm{OCl}-\mathrm{R}$ (Foa et al., 2002) is an 18-item self-report measure of common OCD symptoms, wherein respondents rate bother/distress on a scale of 0 to 4 (not at all to very much). The OCI-R assesses six primary subdomains: (a) washing, (b) obsessing, (c) hoarding, (d) ordering, (e) checking, and ( $f$ ) neutralizing. Overall scores on the $\mathrm{OCI}-\mathrm{R}$ range between 0 and 72 , and subscale scores range between 0 and 12. The OCI-R possesses good psychometric properties ( $\alpha$ s between .81 and .93) and adequate testretest reliability (.57-.91; Foa et al., 2002).

Penn Inventory of Scrupulosity (PIOS)The PIOS (Abramowitz et al., 2002) is a 19-item self-report measure developed to assess scrupulosity in the context of OCD. The PIOS consists of two subscales: one measuring the fear of having committed sin and another measuring fear concerning God's punishment. Items are rated on a 5-point scale ranging from 0 (never) to 4 (constantly). The PIOS has strong internal consistency $(\alpha=.91)$ and appropriate convergent and discriminate validity (Abramowitz et al., 2002).

Yale-Brown Obsessive Compulsive Scale (Y-BOCS)The Y-BOCS (Goodman et al., 1989a, 1989b) is an assessor-rated measure of OCD symptom severity with two subscales: obsession and compulsion. The score for each subscale ranges from 0 to 20, with a total score range from 0 to 40 . The Y-BOCS has acceptable interrater reliability for the total score (between .80 and .97) and a 2-week test-retest reliability of between .81 and .97 .

BDI-IIThe BDI-II (Beck, 1996) is a 21-item measure of depression-related symptoms like sadness, pessimism, loss of pleasure, suicidal thoughts, and so on. It has strong psychometric properties (Beck, Epstein, Brown, \& Steer, 1988), showing good internal consistency, high test-retest reliability $(r=.93)$, and a high correlation with the original BDI ( $r=.93$; Beck, 1996).

Quality of Life Scale (QOLS)The QOLS (Burckhardt, Woods, Schultz, \& Ziebarth, 1989) is a 16-question assessment that measures overall life satisfaction. Items are rated on a 7-point scale ranging from $1=$ terrible to 7 = delighted. A minimum score for the assessment is 16 and a maximum score is 112 , with higher scores indicating better quality of life. The QOLS has been found to be internally consistent ( $\alpha$ 
between .89 and .92), with acceptable temporal stability ( $r$ between .78 and .84 over a 3-week period; Burckhardt et al., 1989).

Santa Clara Strength of Religious Faith Questionnaire (SCSORF)The SCSORF (Plante \& Boccaccini, 1997) is a 10-item measure scored on a 4-point scale measuring strength of religious faith (e.g., "My religious faith is extremely important to me."). Answers range from 1 = strongly disagree to $4=$ strongly agree. Research has found coefficient alphas between .94 and .95 and split-half reliability between .90 and .96 . Due to clerical error, Questions 9 and 10 were omitted from this measure. Thus, results from this measure should be viewed cautiously in this study.

Psychological Process Measure.

Acceptance and Action Questionnaire-II (AAQ-II)The AAQ-II (Bond et al., 2011) is a measure of psychological flexibility. Seven questions are rated on a 7-point Likert-type scale, ranging from $1=$ never true to 7 = always true. Higher scores on the AAQ-II are reflective of greater experiential avoidance and immobility, whereas lower scores reflect greater acceptance and action. The mean alpha coefficient for the AAQ-II is .84, and the 3- and 12-month test-retest reliability is .81 and .79, respectively (Bond et al., 2011).

Treatment Acceptability Measure.

Treatment Evaluation Inventory-Short Form (TEI-SF)The acceptability of this treatment was measured with the TEI-SF (Kelley, Heffer, Gresham, \& Elliott, 1989). Questions are rated on a 5-point Likert-type scale ranging from "strongly disagree" to "strongly agree," with some of the responses requiring reverse-scoring. Two of the questions from the original TEI-SF were omitted, because they dealt specifically with issues surrounding family interventions. Total scores on this version of the TEI-SF range from a minimum of 5 to a maximum of 35 . The TEI-SF has shown to be internally consistent $(\alpha=.85)$.

Reliability Checks for SCID and Y-BOCS

All assessment sessions were video recorded. A trained graduate student viewed and scored $20 \%$ of the Y-BOCS and $20 \%$ of the SCID assessments for interrater reliability. Checking for interrater reliability involved viewing the sections of video where the SCID and Y-BOCS occurred and completing these measures without knowledge of previous scores. Each item on the Y-BOCS was compared, and the presence or absence of diagnosis was compared for the SCID. There was $97 \%$ agreement on the Y-BOCS (with the one disagreement having a 2-point difference). The assessor score was retained. There was $100 \%$ agreement on the scoring of the SCID. It should be noted that these were not independently conducted assessments but that the second assessor had to complete the assessments based off the primary assessor's questioning.

Procedure

A multiple baseline across participants design was used in this study. The primary dependent variables tracked for each participant throughout the entire study (pretreatment, posttreatment, and follow-up) were the frequency of compulsions, along with a measure of avoided valued activities. These data were collected daily by the participants, and reported via a secure Internet web form on a daily basis. To begin, a single participant was selected to start tracking daily compulsions and avoided valued activities. After baseline was established, treatment commenced. The following four participants started 
treatment after baseline durations that were longer than the previous participant. Thus, in this particular study, Participants 4 and 5 served as controls for Participants 1 to 3 . The staggered baseline durations show that the effects are not merely due to participating in baselines of certain durations. Also, all treatments were initiated at different real times, so the results should not be due to a single environmental event. Finally, the treatment was tested within each participant, thus showing replication across participants. A final advantage to this design was that it afforded a scientifically sound way to measure treatment impact with a relatively small sample size, and allowed all participants to receive the active treatment without the need for control conditions.

The secondary dependent variables were collected from the Y-BOCS, OCI-R, BDI-II, SCSORF, and QOLS, to support and verify findings from the self-monitoring. Formal pretreatment, posttreatment, and 3-month follow-up assessment sessions occurred for each participant. All measures previously listed were completed at all assessment points with the exception of the SCID, which was only completed at pretreatment, and the TEI-SF, which was only completed at posttreatment. To monitor weekly progress of the main ACT process (psychological flexibility), the AAQ-Il was administered multiple times during pretreatment (when possible), on a weekly basis from pretreatment to posttreatment, and at follow-up. Collection of these data helps to provide some information regarding the degree and timing of reductions in psychological inflexibility in comparison with compulsion frequency. For example, the model of change would not be supported if reductions in symptoms were seen prior to any reductions in psychological flexibility. Whereas, it is more supportive of the model if psychological flexibility and compulsions decrease together or psychological flexibility decreases prior to compulsions.

\section{Treatment}

ACT for OCD (Twohig, 2009; Twohig et al., 2006; Twohig et al., 2010) was utilized in this study. The underlying model of ACT centers around facilitating the following six core processes: (a) learning to accept (vs. fight against) the presence of unwanted intrusive thoughts; (b) learning to defuse from or disempower language in certain situations, including when obsessions are occurring; (c) coming to view the self as the context within which thoughts and feelings occur versus viewing one's self as synonymous with the content of thoughts; (d) an emphasis on contact with the present moment or mindfulness; (e) the identification and/or cultivation of core life values, thereby increasing motivation to engage in treatment and life; and (f) the fostering of committed action in alignment with these values. ACT for OCD was implemented in eight, weekly, 1 to 1.5 hour sessions.

ACT relies heavily on the use of metaphor and exercises as an interactive pedagogical device to help foster a deeper incorporation of these core processes, along with weekly, behavior-based homework assignments to allow greater incorporation of learned skills. All sessions following Session 1 had the following components (and thus are not necessarily listed in Table 2): assessment of functioning, review of components, and homework assignments. The third author served as the therapist for Participant 1 and the first author served as the therapist for all remaining participants. The first author was trained and supervised by the third author. There were no notable differences as a result of therapist.

Integrity of Treatment Administration

All sessions were video recorded. The third author reviewed intake material, confirmed the OCD diagnoses, and supervised Y-BOCS scores for accuracy. Twenty-five percent of all therapy sessions (10 out of 40 ) were rated for treatment integrity by the second author, a senior graduate assistant who has 
been trained to competency in treatment integrity of ACT for OCD (Twohig et al., 2010). The coding system for the rating was based on a previously utilized scoring system (Twohig et al., 2006). Overall therapist competency and overall adherence to the ACT model were rated with the following scale: $1=$ not at all adherent/competent to $5=$ extremely adherent/competent. Individual assessment of the six core ACT processes, along with individual assessment of therapy actions that are less consistent or inconsistent with ACT, were also rated. Therapy actions deemed to be less consistent or inconsistent with ACT included discussion of cognitive content, indications that thoughts and feelings cause behaviors, behavior management to regulate thoughts/feelings, and ERP procedures (intentionally invoking obsessions in-session, collecting SUDS (subjective units of distress) ratings, teaching response prevention, etc.). Values of ratings were as follows: 5 = occurred with high frequency and was covered in a very in-depth manner, $4=$ occurred with relatively high frequency and was addressed in a moderately in-depth manner, $3=$ occurred several times and was covered at least once in a moderately in-depth manner, 2 = occurred at least once and not in an in-depth manner, and $1=$ the variable was never explicitly covered. Overall adherence to the manual and overall therapist competence were highly rated ( $M=4.0, S D=0.8$, and $M=4.3, S D=0.7$, respectively). Means for the various $A C T$ components over the eight sessions were as follows: acceptance, $M=3.3(S D=1.4)$; defusion, $M=2.2(S D=1.1)$; self as context, $M=1.4$ ( $S D=0.7)$; present moment, $M=1.5$ ( $S D=0.7)$; values, $M=2.9$ ( $S D=1.6)$; and committed action, $M=2.7$ ( $S D=1.2$ ). Means for therapy actions that are less consistent or inconsistent with ACT were as follows: discussion of content of obsessions, $M=2.0$ ( $S D=1.1)$; cognitive model, $M=$ $1.0(S D=0)$; behavior management, $M=1.0(S D=0)$; and in-session exposure, $M=1.0(S D=0)$.

An additional scoring system was also used for this study, in an attempt to measure treatment content on a per-minute basis. The same senior graduate student administered this scoring system. Out of a total of $845 \mathrm{~min}$ of assessed therapy over eight sessions, therapy time was generally distributed as follows (note some overlap): general assessment: $380 \mathrm{~min}$ (45\% of total), acceptance: $212 \mathrm{~min}$ (25\% of total), values: $158 \mathrm{~min}$ (19\% of total), committed action: $93 \mathrm{~min}$ (11\% of total), defusion: $70 \mathrm{~min}$ ( $8 \%$ of total), self-as-context: $17 \mathrm{~min}$ ( $2 \%$ of total), present moment: $14 \mathrm{~min}$ ( $2 \%$ of total), discussion of obsessions content: $53 \mathrm{~min}(6 \%)$, and in-session exposure: $0 \mathrm{~min}$ ( $0 \%$ of total).

Results

Individual rates of self-monitored compulsions and avoided valued activities are presented for each participant (Figures 1 and 2). Individual scores at pretreatment, posttreatment, and 3-month follow-up are in Table 3. Group averages across all measures are presented in the text.

Figure 1. Daily frequency of compulsions (diamonds/solid line) and weekly ACT process scores (triangles/dotted line) for the five participants in baseline and treatment phases.

Note: $\mathrm{ACT}=$ acceptance and commitment therapy; $\mathrm{P}=$ participant; $\mathrm{AAQ}-\mathrm{II}=$ Acceptance and Action Questionnaire II.

Figure 2. Daily frequency of avoided valued activities (diamonds/solid line) and weekly ACT process scores (triangles/dotted line) for the five participants in baseline and treatment phases.

Note: $\mathrm{ACT}$ = acceptance and commitment therapy; $\mathrm{P}=$ participant; $\mathrm{AAQ}-\mathrm{II}=$ Acceptance and Action Questionnaire II.

Compulsions and Avoided Valued Activities Frequency 
Participant 1. The pretreatment average for Participant 1's daily compulsions was $M=10.0(S D=2.3)$. Her compulsions reduced by $50 \%$ by Day 36 of treatment, further reduced to $M=1.8(S D=1.3)$ by posttreatment, and to $\mathrm{M}=1.6(\mathrm{SD}=0.8$ ) by follow-up. The pretreatment average for Participant 1's daily avoided valued activities was $\mathrm{M}=0.8(\mathrm{SD}=0.8)$. Her reported avoided activities were reduced to 0 by Day 36 of treatment, and this rate was maintained through posttreatment $(M=0.0, S D=0.0)$, rising slightly at follow-up to $\mathrm{M}=0.1(\mathrm{SD}=0.4)$.

Participant 2. The pretreatment average for Participant 2's daily compulsions was M = 52.1 (SD $=23.0$ ). His compulsions reduced by $52 \%$ by Day 66 of treatment, and reduced to $M=13.5$ (SD = 4.3) by posttreatment, and $\mathrm{M}=8.7$ ( $S D=4.4$ ) by follow-up. The pretreatment average for Participant 2's daily avoided valued activities was $M=3.0(S D=3.2$ ). His avoided activities were reduced to 0 by Day 66 of treatment, and this rate was maintained through posttreatment $(M=0.0, S D=0.0$ ) and at follow-up (M $=0.0, \mathrm{SD}=0.0$ ).

Participant 3. The pretreatment average for Participant 3's daily compulsions was $M=5.3(S D=1.4)$. His compulsions were reduced by $62 \%$ by Day 41 , reduced to $M=2.4(S D=0.5)$ by posttreatment, and to $M$ $=0.5(\mathrm{SD}=0.8)$ by follow-up. The pretreatment average for Participant 3's daily avoided valued activities was $\mathrm{M}=2.2(\mathrm{SD}=0.6)$. His avoided activities were reduced by $54 \%$ by Day 56 of treatment, reduced to $\mathrm{M}=0.9(\mathrm{SD}=0.4)$ by posttreatment, and then decreased to 0 at follow-up.

Participant 4. The pretreatment average for Participant 4's daily compulsions was $M=42.1(S D=14.2)$. Her compulsions were reduced by $64 \%$ by Day 78 of treatment, and reduced to $M=6.6(S D=4.4)$ by posttreatment, and $\mathrm{M}=2.9$ ( $S D=0.9$ ) by follow-up. The pretreatment average for Participant 4's daily avoided valued activities was $M=21.8(S D=7.3$ ). Her avoided activities reduced by $77 \%$ by Day 78 of treatment, and reduced to $M=1.7(S D=1.3)$ by posttreatment and to $M=1.6(S D=1.1)$ by follow-up.

Participant 5. The pretreatment average for Participant 5's daily compulsions was $M=15.6(S D=8.1$ ). Her compulsions reduced by $55 \%$ by Day 66 of treatment, and reduced to $M=3.9(S D=1.2)$ by posttreatment, but increased to $M=8.0$ ( $S D=1.6$ ) by follow-up. The pretreatment average for Participant 5's daily avoided valued activities was $\mathrm{M}=2.0(\mathrm{SD}=1.6)$. Her avoided activities reduced by $51 \%$ by Day 58 of treatment, and reduced to $M=1.1(S D=1.1)$ by posttreatment, and to $M=0.9(S D=$ $0.4)$ by follow-up.

Overall. Aggregating across all five participants, average daily compulsions were $M=25.0(S D=20.8)$ at pretreatment, and then decreased by $74 \%$ to $M=5.6(S D=4.8)$ at posttreatment, and by $80 \%$ to $M=4.3$ $(S D=3.8)$ at follow-up. Average daily avoided valued activities were $M=6.0(S D=8.9)$ at pretreatment, and then decreased by $79 \%$ to $M=0.7(S D=0.7)$ at posttreatment, and by $87 \%$ to $M=0.5(S D=0.7)$ at follow-up.

\section{OCD Measures}

Average $\mathrm{Y}$-BOCS scores were $\mathrm{M}=25.4$ ( $\mathrm{SD}=5.6$ ) at pretreatment, and decreased by $51 \%$ to $\mathrm{M}=12.4$ (SD $=5.1$ ) at posttreatment, and by $54 \%$ to $\mathrm{M}=11.8(\mathrm{SD}=2.9)$ at follow-up. OCI-R scores followed a similar trend, measuring $M=31.8(S D=12.3)$ at pretreatment, decreasing by $55 \%$ to $M=14.4(S D=4.7)$ at posttreatment, and rising slightly to $M=16.4(S D=7.5)$ at follow-up, for a pretreatment to follow-up reduction of $48 \%$. Scrupulosity symptom severity mean scores (as measured by the PIOS) began at $\mathrm{M}=$ $54.6(S D=10.7)$ at pretreatment, decreasing by $50 \%$ to $M=27.2(S D=3.8)$ at posttreatment, staying 
relatively constant at $M=26.8(S D=8.4)$ during follow-up. $O C D$ measure subscores were consistent with total scores and are available from corresponding authors.

Religious Faith

Notably, while scrupulosity-based OCD declined, religious faith (as measured by the SCSORF) declined only $4 \%$ from pretreatment $(M=29.2, S D=2.7)$ to posttreatment $(M=28.0, S D=4.6)$, and $7 \%$ from pretreatment to follow-up ( $M=27.3, S D=4.5)$.

Depression

Depression symptom severity as measured by the BDI-II was $\mathrm{M}=30.6$ ( $S D=15.2$ ) at pretreatment, decreasing by $73 \%$ to $M=8.4(S D=3.2$ ) at posttreatment, rising slightly to $M=10.2(S D=4.7)$ at followup for a final pretreatment to follow-up reduction of $67 \%$.

Quality of Life

Quality-of-life scores (as measured by the QOLS) began at $M=60.6(S D=15.7)$ at pretreatment, rising by $26 \%$ to $M=76.6(S D=7.7)$ at posttreatment, rising slightly again to $M=77.8(S D=10.5)$ during followup for a final pretreatment to follow-up increase of $28 \%$.

Psychological Processes of Change

Psychological process change as measured by the AAQ-II seemed to occur across the participants as expected (Figures 1 and 2). The mean score on the AAQ-II across all participants was $M=36.2(S D=5.2)$ at pretreatment, declining by $40 \%$ to $M=21.6(S D=4.8)$ at posttreatment, declining further to $M=20.6$ $(S D=8.4)$ at follow-up for a final pretreatment to follow-up decrease of $43 \%$. When graphed, declining AAQ-II slopes appear to generally co-occur with declines in both compulsions and avoided valued activities.

Treatment Acceptability

ACT was found to be highly acceptable by all participants, with a mean score of 30 on the TEI-SF at posttreatment, only 5 points below the maximum score of 35 (or $86 \%$ of the maximum score).

Discussion

In this study, five participants diagnosed with scrupulosity-based OCD received eight sessions of ACT in a multiple baseline across participants design. At posttreatment, participants reported a $74 \%$ reduction in self-reported compulsions and a $79 \%$ reduction in avoided valued behaviors, and at 3-month follow-up participants reported an $80 \%$ reduction in compulsions and an $87 \%$ reduction in avoided valued behaviors. At posttreatment, participants averaged notable decreases in Y-BOCS (51\%), OCI-R (55\%), PIOS (50\%), and BDI-II (73\%) scores, and an increase in QOLS (26\%) scores. These results were generally maintained at 3-month follow-up. Finally, whereas scrupulous symptom severity declined considerably, religious faith (as measured by the SCSORF) declined only $4 \%$ from pretreatment to posttreatment and $7 \%$ from pretreatment to follow-up, indicating that the reduction in compulsive religious behavior was not associated with notable changes in faith. Arguably, the reductions seen on the SCSORF could be associated with reductions in compulsive religious or moral behavior. 
The primary process of change measure for this study was the AAQ-II (self-report), which measures the main psychological processes targeted in ACT such as acceptance, defusion, values, and so on. From pretreatment to posttreatment, AAQ-II scores decreased by $40 \%$, which was maintained at follow-up (43\%). Based on a visual assessment of outcome and process data graphed together, it appears as though process change correlated consistently with compulsion and avoided activities behavior change across four out of five participants (Participant 5 being a possible exception). It is theorized that Participant 5's lack of process change correlation might be due to a set of uncharacteristically disruptive life events that occurred toward the end of her course of treatment. In terms of treatment acceptability, ACT was found to be highly acceptable by all five participants, averaging a mean score of 30 on the TEISF at posttreatment, which is only 5 points below the maximum score of 35 (or $86 \%$ ).

The bulk of current OCD research continues to center on either pharmaceutical interventions or ERP. While the past few years have produced a slight uptick in research about ACT for OCD, a considerable amount of work remains for ACT and its role in the treatment of OCD (Tolin, 2009). This study lends further credence to the utility of ACT as a treatment option for OCD. With regard to scrupulosity-based OCD specifically, this study represents the only known psychological treatment outcome study to be conducted exclusively for religious or moral-based OCD. Given the favorable results of the study, additional ACT for scrupulosity-based OCD research is warranted. On one hand, ACT for OCD work can continue as a stand-alone treatment. On the other hand, exposure exercises can fit nicely into the ACT model and can provide great opportunities to practice ACT techniques in session. In addition, exposure exercises can occur outside of session as long as the client focuses on enhancing ACT processes during the exercises. This generally involves a greater focus on acceptance and mindfulness during the exercises, and linking the exercises to one's values. Research will show the utility of ACT alone, or ACT and exposure exercises together, for the treatment of OCD generally and scrupulosity-based OCD specifically.

The results of this study show promise that the use of ACT in the treatment of scrupulosity-based OCD might be of particular utility because of the following: (a) ACT appears to be rated as highly acceptable to scrupulosity clients, potentially leading to low refusal, drop-out, and nonresponse rates (Twohig et al., 2010); (b) ACT is metacognitive and does not need to address religious content, and thus, potentially avoiding therapist need to navigate specific religious doctrines or to interact with the client's ecclesiastical leaders to ensure ethical or effective treatment; and (c) ACT appears to achieve favorable results with scrupulosity in a very short period of time (12 therapy hours per client in this study).

There are several limitations to this study. As a preliminary study, it utilized a small number of participants (five). In addition, the SCID and Y-BOCS assessments were conducted by the same individual who served as the primary therapist (under supervision), although other measures relied on self-report. Though suboptimal, this combination of a small $\mathrm{N}$, assessor administered, and self-report design is a broad, standardly used, and useful combination of outcome assessment procedures (Twohig \& Crosby, 2010; Twohig et al., 2006). Self-monitoring is relied upon for both of the primary dependent variables in this study, and while considered to be a valuable tool for treatment monitoring, self-monitoring can also have modest reactive effects, often in the therapeutically desired direction (Korotitsch \& Nelson-Gray, 1999). While such reactive effects are certainly plausible, it should be noted that the findings for the main dependent variables were supported by multiple additional standardized measures (OCI-R, PIOS) as well as by a therapist-administered measure (Y-BOCS). In addition, the Twohig et al. (2010) study of ACT for OCD did not include self-monitoring and achieved strong results. Nevertheless, there may be 
clinical utility to self-monitoring and ACT over ACT alone for scrupulosity-type OCD, as self-monitoring may help raise awareness of one's symptoms. This will have to be evaluated in future research.

Because most of the compulsions reported in this study were covert or private, all of the participants reported difficulty quantifying their daily compulsions. This led to considerable anxiety (and potentially increased levels of compulsions) for many of the participants, and was particularly burdensome for scrupulous clients, given their frequent drives for moral integrity/honesty. To illustrate, one participant withdrew from the study prior to treatment, citing the excessive burden of counting compulsions as the main concern. Interestingly, another participant withdrew from the study prior to treatment noting that the act of tracking compulsions made him more aware of his behavior, leading to a decrease in his perceived symptom severity.

Regarding treatment, only eight sessions were administered per participant. It is possible that the participants would have achieved additional gains if more sessions were offered. Also, as noted through the treatment integrity scoring, while the therapists were rated a 4 out of 5 on ACT compliance, the therapists occasionally engaged in discussions regarding cognitive (e.g., religious) content, which is of questionable compliance with the ACT model. All five of the participants were Caucasian members of the Church of Jesus Christ of Latter-Day Saints with relatively high education levels, all of which could feasibly impact generalizability. Finally, a more extended follow-up (6 or 12 months) would likely provide more useful outcome data than 3 months. In conclusion, it appears as though ACT shows considerable promise as a treatment for scrupulosity-based OCD, and that further research is warranted.

\section{Authors' Note}

This study was completed as John Dehlin's master's thesis equivalent at Utah State University. A copy of the manual is available from the corresponding author.

\section{Declaration of Conflicting Interests}

The author(s) declared no potential conflicts of interest with respect to the research, authorship, and/or publication of this article.

Funding

The author(s) received no financial support for the research, authorship, and/or publication of this article.

\section{References}

Abramowitz J. S. (2001). Treatment of scrupulous obsessions and compulsions using exposure and response prevention: A case report. Cognitive and Behavioral Practice, 8, 79-85. Crossref

Abramowitz J. S. (2008). Scrupulosity. In Abramowitz J., McKay D., Taylor S. (Eds.), Clinical handbook of obsessive-compulsive disorder and related problems (pp. 157-172). Baltimore, MD: Johns Hopkins University Press.

Abramowitz J. S., Huppert J. D., Cohen A. B., Tolin D. F., Cahill S. P. (2002). Religious obsessions and compulsions in a non-clinical sample: The Penn Inventory of Scrupulosity (PIOS). Behaviour Research and Therapy, 40, 824-838. Crossref 
American Psychiatric Association. (1994). Diagnostic and statistical manual of mental disorders (4th ed.). Washington, DC: Author.

Beck A. T. (1996). Beck Depression Inventory (2nd ed.). San Antonio, TX: The Psychological Corporation.

Beck A. T., Epstein N., Brown G., Steer R. A. (1988). An inventory for measuring clinical anxiety:

Psychometric properties. Journal of Consulting and Clinical Psychology, 56, 893-897. Crossref PubMed.

Bonchek A., Greenberg D. (2009). Compulsive prayer and its management. Journal of Clinical

Psychology, 65, 396-405. Crossref PubMed.

Bond F. W., Hayes S. C., Baer R. A., Carpenter K. M., Guenole N., Orcutt H. K., Zettle R. D. (2011).

Preliminary psychometric properties of the Acceptance and Action Questionniare-II: A revised measure of psychological inflexibility and experiential avoidance. Behavior Therapy, 42, 676-688. Crossref PubMed.

Burckhardt C. S., Woods S. L., Schultz A. A., Ziebarth D. M. (1989). Quality of life of adults with chronic illness: A psychometric study. Research in Nursing \& Health, 12, 347-354. Crossref PubMed.

Cefalu P. (2010). The doubting disease: Religious scrupulosity and obsessive-compulsive disorder in historical context. Journal of Medical Humanities, 31, 111-125. Crossref PubMed.

Ciarrocchi J. W. (1995). The doubting disease: Help for scrupulosity and religious compulsions. New York, NY: Paulist.

Fallon B. A., Liebowitz M. R., Hollander E., Schneier F. R. (1990). The pharmacotherapy of moral or religious scrupulosity. Journal of Clinical Psychiatry, 51, 517-521. PubMed.

First M. B., Spitzer R. L., Gibbon M., Williams J. B. W. (2002). Structured Clinical Interview for DSM-IV-TR Axis I Disorders, Research Version, Patient Edition (SCID-I/P). New York: Biometrics Research, New York State Psychiatric Institute.

Foa E. B., Huppert J. D., Leiberg S., Langner R., Kichic R., Hajcak G., Salkovskis P. M. (2002). The Obsessive-Compulsive Inventory: Development and validation of a short version. Psychological Assessment, 14, 485-496. Crossref PubMed.

Garcia H. A. (2008). Targeting Catholic rituals as symptoms of obsessive compulsive disorder: A cognitive-behavioral and psychodynamic, assimilative integrationist approach. Pragmatic Case Studies in Psychotherapy, 4(2), 1-38. Crossref.

Goodman W. K., Price L. H., Rasmussen S. A., Mazure C. (1989a). The Yale-Brown Obsessive Compulsive Scale: I. Development, use, and reliability. Archives of General Psychiatry, 46, 1006-1011. Crossref PubMed.

Goodman W. K., Price L. H., Rasmussen S. A., Mazure C. (1989b). The Yale-Brown Obsessive Compulsive Scale: II. Validity. Archives of General Psychiatry, 46, 1012-1016. Crossref PubMed.

Greenberg D., Witztum E. (2001). Treatment of strictly religious patients. In Pato M. T., Zohar J. (Eds.), Current treatments of obsessive-compulsive disorder (2nd ed., pp. 173-191). Washington, DC: American Psychiatric Association. 
Hayes S. C., Strosahl K. D., Wilson K. G. (1999). Acceptance and commitment therapy: An experiential approach to behavior change. New York, NY: Guilford.

Huppert J. D., Siev J. (2010). Treating scrupulosity in religious individuals using cognitive-behavioral therapy. Cognitive and Behavioral Practice, 17, 382-392. Crossref

Jackson J. L. (1999). Psychometric considerations in self-monitoring assessment. Psychological Assessment, 11, 439-447. Crossref

Jacobson N. S., Truax P. (1991). Clinical significance: A statistical approach to defining meaningful change in psychotherapy research. Journal of Consulting and Clinical Psychology, 59, 12-19. Crossref PubMed.

Kelley M. L., Heffer R. W., Gresham F. M., Elliott S. N. (1989). Development of a modified treatment evaluation inventory. Journal of Psychopathology and Behavioral Assessment, 11, 235-247. Crossref

Korotitsch W. J., Nelson-Gray R. O. (1999). An overview of self-monitoring research in assessment and treatment. Psychological Assessment, 11, 415-425. Crossref

Meuret A. E., Twohig M. P., Hayes S. C., Rosenfield D., Craske M. G. (2012). Brief acceptance and commitment therapy and exposure for panic disorder: A pilot study. Cognitive and Behavioral Practice, 19, 606-618. Crossref

Miller C. H., Hedges D. W. (2008). Scrupulosity disorder: An overview and introductory analysis. Journal of Anxiety Disorders, 22, 1042-1058. Crossref PubMed.

Plante T. G., Boccaccini M. T. (1997). The Santa Clara Strength of Religious Faith Questionnaire. Pastoral Psychology, 45, 375-387. Crossref

Segal D. L., Hersen M., Van Hasselt V. B. (1994). Reliability of the Structured Clinical Interview for DSMIII-R: An evaluative review. Comprehensive Psychiatry, 35, 316-327. Crossref PubMed.

Tolin D. F. (2009). Alphabet soup: ERP, CT, and ACT for OCD. Cognitive and Behavioral Practice, 16, 4048. Crossref

Twohig M. P. (2009). The application of acceptance and commitment therapy to obsessive-compulsive disorder. Cognitive and Behavioral Practice, 16, 18-28. Crossref

Twohig M. P., Crosby J. M. (2010). Acceptance and commitment therapy as a treatment for problematic Internet pornography viewing. Behavior Therapy, 41, 285-295. Crossref PubMed.

Twohig M. P., Hayes S. C., Masuda A. (2006). Increasing willingness to experience obsessions: Acceptance and commitment therapy as a treatment for obsessive compulsive disorder. Behavior Therapy, 37, 3-13. Crossref PubMed.

Twohig M. P., Hayes S. C., Plumb J. C., Pruitt L. D., Collins A. B., Hazlett-Stevens H., Woidneck M. R. (2010). A randomized clinical trial of acceptance and commitment therapy vs. progressive relaxation training for obsessive compulsive disorder. Journal of Consulting and Clinical Psychology, 78, 705-716. Crossref PubMed.

Author Biographies 
John P. Dehlin, MS, is a doctoral student in psychology at Utah State University. His research focuses on the nexus of religion and mental health.

Kate L. Morrison, BA, is a doctoral student in psychology at Utah State University. Her research and clinical interests are in ACT, delay discounting, and treatment of anxiety disorders.

Michael P. Twohig, PhD, is an associate professor of Psychology at Utah State University. His research focuses on the treatment of anxiety disorders using exposure-based therapies and acceptance and commitment therapy. 